\title{
Study on Anodic Oxidation and Sealing of Aluminum Alloy
}

\author{
Ye Wan ${ }^{*}$, Huan Wang, Yundian Zhang, Xiumei Wang, Yanbo Li
}

School of Materials Science and Engineering, Shenyang Jianzhu University, Shenyang 110168, China *E-mail: ywan@sjzu.edu.cn

doi: $10.20964 / 2018.02 .78$

Received: 9 October 2017 / Accepted: 15 December 2017 / Published: 28 December 2017

\begin{abstract}
Alumina films were prepared on the surfaces of 2024 aluminum alloy by the anodic oxidation, the sealing and the coloring methods. The films were studied via scanning electron microscopy, X-ray diffraction, the surface roughness, the indentation hardness, the abrasion resistance and the corrosion resistance tests. The results revealed that porous alumina was detected on the surface of the aluminum alloy samples after the anodic oxidation treatment and the amount of the pores decreased with the oxidation time. The anodic oxidation film became denser with the oxidation time and enhanced the corrosion resistance of 2024 aluminum alloy. The anodic oxidation process decreased the surface roughness of aluminum alloy. The samples' hardness, abrasion resistance and corrosion resistance were increased by the sealing process for the anodic oxidation films. The combination procedure of anodic oxidation and sealing with boiling water improved the hardness and the abrasion resistance of the samples greatly.
\end{abstract}

Keywords: Aluminum alloy; Anodic oxidation; Alumina film; Sealing; Performance test

\section{FULL TEXT}

(C) 2018 The Authors. Published by ESG (www.electrochemsci.org). This article is an open access article distributed under the terms and conditions of the Creative Commons Attribution license (http://creativecommons.org/licenses/by/4.0/). 